\title{
Expression of prostasin and its inhibitors during colorectal cancer carcinogenesis
}

\author{
Joanna Selzer-Plon ${ }^{1}$, Jette Bornholdt ${ }^{1}$, Stine Friis ${ }^{1}$, Hanne C Bisgaard ${ }^{1}$, \\ Inger MB Lothe ${ }^{2}$, Kjell M Tveit ${ }^{3}$, Elin H Kure ${ }^{2,3,4}$, Ulla Vogel ${ }^{5}$ and \\ Lotte K Vogel*1
}

\begin{abstract}
Address: ${ }^{1}$ Department of Cellular and Molecular Medicine, Faculty of Health Science, University of Copenhagen, Denmark, ${ }^{2}$ Department of Pathology, Ulleval University Hospital, Oslo, Norway, ${ }^{3}$ The Cancer Centre, Ulleval University Hospital, 0407 Oslo, Norway, ${ }^{4}$ Department of Environmental and Health Studies, Telemark University College, Bø, Norway and ${ }^{5}$ National Food Institute, Technical University of Denmark, Soborg, Denmark and the National Research Centre for the Working Environment, Copenhagen, Denmark

Email: Joanna Selzer-Plon - selzer@sund.ku.dk; Jette Bornholdt - bornholdt@sund.ku.dk; Stine Friis - sfriis@sund.ku.dk; Hanne C Bisgaard - hcb@sund.ku.dk; Inger MB Lothe - ilot@uus.no; Kjell M Tveit - kjell.tveit@uus.no; Elin H Kure - elin.kure@uus.no; Ulla Vogel - ulbvo@food.dtu.dk; Lotte K Vogel* - vogel@sund.ku.dk

* Corresponding author
\end{abstract}

Published: 25 June 2009

BMC Cancer 2009, 9:20I doi:10.1 I86/I47|-2407-9-201
Received: 3 February 2009

Accepted: 25 June 2009

This article is available from: http://www.biomedcentral.com/l47I-2407/9/20 I

(c) 2009 Selzer-Plon et al; licensee BioMed Central Ltd.

This is an Open Access article distributed under the terms of the Creative Commons Attribution License (http://creativecommons.org/licenses/by/2.0), which permits unrestricted use, distribution, and reproduction in any medium, provided the original work is properly cited.

\begin{abstract}
Background: Clinical trials where cancer patients were treated with protease inhibitors have suggested that the serine protease, prostasin, may act as a tumour suppressor. Prostasin is proteolytically activated by the serine protease, matriptase, which has a very high oncogenic potential. Prostasin is inhibited by protease nexin-I (PNI) and the two isoforms encoded by the mRNA splice variants of hepatocyte growth factor activator inhibitor-I (HAII), HAI-IA, and HAI-IB.
\end{abstract}

Methods: Using quantitative RT-PCR, we have determined the mRNA levels for prostasin and $P N-I$ in colorectal cancer tissue $(n=116)$, severe dysplasia $(n=13)$, mild/moderate dysplasia $(n=93)$, and in normal tissue from the same individuals. In addition, corresponding tissues were examined from healthy volunteers $(n=23)$. A part of the cohort was further analysed for the mRNA levels of the two variants of HAI-I, here denoted HAI-IA and HAIIB. mRNA levels were normalised to $\beta$-actin. Immunohistochemical analysis of prostasin and HAI-I was performed on normal and cancer tissue.

Results: The mRNA level of prostasin was slightly but significantly decreased in both mild/moderate dysplasia ( $\mathrm{P}$ $<0.00 \mathrm{I})$ and severe dysplasia $(\mathrm{p}<0.0 \mathrm{I})$ and in carcinomas $(\mathrm{p}<0.05)$ compared to normal tissue from the same individual. The mRNA level of $P N-I$ was more that two-fold elevated in colorectal cancer tissue as compared to healthy individuals $(P<0.001)$ and elevated in both mild/moderate dysplasia $(p<0.01)$, severe dysplasia $(p<0.05)$ and in colorectal cancer tissue $(p<0.00 \mathrm{I})$ as compared to normal tissue from the same individual. The mRNA levels of HAI-IA and HAI-IB mRNAs showed the same patterns of expression. Immunohistochemistry showed that prostasin is located mainly on the apical plasma membrane in normal colorectal tissue. A large variation was found in the degree of polarization of prostasin in colorectal cancer tissue.

Conclusion: These results show that the mRNA level of $P N-I$ is significantly elevated in colorectal cancer tissue. Future studies are required to clarify whether down-regulation of prostasin activity via up regulation of $\mathrm{PN}-\mathrm{I}$ is causing the malignant progression or if it is a consequence of it. 


\section{Background}

Extracellular proteases and protease inhibitors are believed to play an important role during carcinogenesis in many different ways such as degrading the extracellular matrix in order to facilitate invasive growth and activating signal molecules. In accordance with this, proteases were mostly thought of as promoters of carcinogenesis. However, clinical trials where cancer patients were treated with broad-range protease inhibitors have shown that proteases can act as tumour suppressors [1]. Studies using loss-of-function animal models have further confirmed the existence of extra-cellular proteases with anti-tumour properties [2-4]. Prostasin is a relatively unknown extracellular serine protease suspected to play a role as tumour suppressor [1].

Prostasin is a glycosylphosphatidylinositol (GPI)anchored trypsin-like protease expressed in most epithelial cells $[5,6]$. It is to some degree shed from the membrane and found as a soluble enzyme [7]. The proteolytical activity of prostasin can be inhibited by protease nexin-1 (PN-1) [8,9] also known as glia-derived nexin (GDN) or serpin E2 [10] and by the two isoforms of hepatocyte growth factor activator inhibitor-1 (HAI-1), probably originating from two mRNA splice variants of $H A I-1$, here denoted HAI-1A, and HAI-1B [11]. HAI-1B differs from HAI-1A by a 16-amino acid insertion [12]. Prostasin is part of the matriptase-prostasin proteolytic cascade regulating terminal epidermal differentiation [13]. Matriptase is thought to be the first protease in the cascade due to its ability to auto-activate $[14,15]$ and because prostasin is activated by a matriptase-catalysed cleavage [13]. The downstream target for prostasin is unclear but the matriptase-prostasin cascade eventually regulate the processing of the differentiation marker filaggrin $[16,17]$ and is essential for establishment of epidermal integrity $[17,18]$. It has furthermore been shown that prostasin can activate the epithelial sodium channel (ENaC) [19] and cleave the epidermal growth factor receptor [20] but may very well also have other substrates. Matriptase and prostasin share the same inhibitors, as both are inhibited by HAI-1A, HAI-1B [11,12], and PN-1 [21]. Using transgenic mice it has been shown that deregulated matriptase causes carcinogenesis. Even a modest over-expression of matriptase in the skin of transgenic mice caused spontaneous squamous cell carcinoma in $70 \%$ of the mice [22]. Simultaneous over-expression of the matriptase inhibitor HAI-1 completely negated the oncogenic effects of matriptase [22]. Although not known it is unlikely that the oncogenic properties of matriptase are exerted via activation of prostasin as prostasin overexpression has been shown to cause reduced in vitro invasiveness in both prostate and mammary cancer cell lines $[23,24]$ and high prostasin mRNA levels correlates with longer survival for gastric cancer patients [25].
Prostasin is expressed in most epithelial cells and could potentially play a role in most types of cancer. Prostasin has been shown to be down-regulated in gastric cancers [25] and prostate cancer [26]. The enzymatic activity of prostasin may be regulated by several mechanisms one of them being by regulating the mRNA expression levels of its inhibitors PN-1, HAI-1A, and HAI-1B. Elevated PN-1 levels have been found in pancreatic, breast and oral cancers [27-29]. PN-1 does not seem to be a specific inhibitor for prostasin and matriptase as it also inhibits thrombin, trypsin, plasmin and plasminogen activators [30-32] and functions as a neurite growth promoting factor in neuroblastoma cells [33]. HAI-1A and HAI-1B are also non specific inhibitors for prostasin and matriptase as they also inhibit hepatocyte growth factor activator and trypsin [12]. No physiological difference between HAI-1A and HAI-1B has been found. We have previously observed that the HAI-1 mRNA levels are decreased during colorectal cancer carcinogenesis in both normal and affected tissue from individuals with colorectal cancer adenomas and carcinomas as compared to healthy individuals using an assay that does not differentiate between $H A I-1 A$ and $H A I-1 B$ [34]. Likewise HAI-1 has been shown to be downregulated in renal cell carcinomas [35] and in gastric and colorectal cancer [36].

In the present study we have investigated the mRNA levels of prostasin and its inhibitors PN-1, HAI-1A, and HAI-1B, during colorectal cancer carcinogenesis in humans.

\section{Methods \\ Subject population}

The KAM cohort (Kolorektal cancer, Arv og Miljø) is based on the screening group of the Norwegian Colorectal Cancer Prevention study (the NORCCAP study) in the county of Telemark, Norway [37]. Additionally, a series of colorectal cancer cases were recruited to the KAM cohort from routine clinical work at Telemark Hospital in Skien and Ulleval University Hospital in Oslo. The ID number for the NORCCAP study at Clinicaltrials.gov is NCT00119912 [38]. In the NORCCAP study a total of 20,780 men and women, age distribution 50-64 years, drawn randomly from the population registries in Oslo (urban) and the county of Telemark (mixed urban and rural) were invited to have a flexible sigmoidoscopy (FS) screening examination with or without $(1: 1)$ an additional faecal occult blood test (FOBT). 777 (4\%) individuals were excluded according to exclusion criteria [37]. The KAM biobank currently consists of 234 colorectal cancer cases, 1044 cases with adenomas (229 high-risk, 762 low-risk and 53 hyperplastic polyps) and 400 controls. Controls were defined as individuals with normal findings at the time of FS. The KAM study is approved by the Regional Committee for Medical Research Ethics and the Norwegian Data Inspectorate. In the present study we 
have analyzed cases with carcinoma $(\mathrm{n}=116)$, cases with adenoma $(n=106)$ and controls that were polyp-free at time of FS $(n=23)$. Each case was classified according to the degree of malignancy in the lesion. For individuals with adenoma a sample of control tissue was collected 30 $\mathrm{cm}$ from the anus. Control samples from healthy individuals were taken from individuals, where no adenomas or carcinomas could be identified with FS. The histology of the adenomas was examined independently by two histopathologists to categorize the degree of dysplasia as either mild/moderate $(n=93)$ or severe $(n=13)$. They reached consensus in all cases. Cases of dysplasia were also classified as either low- or high-risk according to the size and/or differentiation state of the adenoma. A highrisk adenoma is defined as an adenoma measuring more than $10 \mathrm{~mm}$ in diameter and/or with villous components or showing severe dysplasia. [37]. The distribution of gender and age among controls and cases with carcinoma or adenoma of the colon is shown in Table 1.

\section{RT-PCR}

Total RNA was purified from tissue as recommended by the manufacturers using E.Z.N.A. Total RNA Kit II (VWR, Copenhagen, Denmark). The tissue samples were frozen in liquid as soon as possible after surgery and were stored in liquid $\mathrm{N}_{2}$ until RNA purification. RNA purification included a DNAse treatment. cDNA synthesis was performed on approximately 200 ng RNA per $20 \mu \mathrm{l}$ using High-Capacity cDNA Archive Kit (Applied Biosystems, Denmark). Quantitative RT-PCR for prostasin was performed on the ABI7300 sequence detection system (Applied Biosystems) in Universal Mastermix (Applied Biosystems) using 160/100 nM probe and 600/200 nM primers for prostasin and $P N-1$, respectively. For detection of prostasin mRNA, primers and probes were: $\mathrm{F}$, 5' GGCCTCCACTGCACTGTCA 3'; R,5' AGTTACACGTCTCACGACTGATCAG ' 3 '; probe, 5'-FAM-CAGTGAGCCTCCTGACGCCCAAG-BHQ-3'. For detection of PN-1 mRNA, primer and probes were: $\mathrm{F}$, 5' CCTCCATGTTTCTCATATCTTGCA 3'; R, 5' ACCAGGGAGGCGATGATCT 3'; probe, 5'FAM-AAGCTTCAGCAGCAACAACTGCAATTCTCA-BHQ-3'. Primers were designed within different exons and with probes covering the exon-exon border to prevent amplification of genomic DNA. DNA coding for $H A I-1$ gives rise to two mRNA's coding for two proteins where the amino acids sequence differs by 16 residues [12]. We have previously measured the HAI-1 mRNA using a probe/primer set that detects both $H A I-1 A$ and $H A I-1 B$. For this study we have designed new sets of probe/primers specific for either HAI-1A or HAI-1B. Assays for HAI-1A and HAI-1B were performed using 300 $\mathrm{nM}$ probe and $100 \mathrm{nM}$ primers. Primers and probes for detection of HAI-1A were: F, 5'AGA TCT GCA AGA GTT TCG TTT ATG G-3'; R, 5'-GGT GCC AGA GCA CAC TGG AT-3'; probe, 5'-FAM-TGT GCA AGG CCC CTC CAT GGA A-BHQ-1-3'. Primers and probes for detection of $H A I-1 B$ were: F, 5'-ATC TGC AAG AGT TTC GTT TAT GGA-3'; R, 5'GGT GCC AGA GCA CAC TGG AT-3'; probe, FAM-CCT TTG AGA GGC AGC TC-MGBNFQ. HAI-1A and HAI-1B probes were obtained from Applied Biosystems. $\beta$-actin primers and probes were obtained as a pre-developed assay (cat. no. 4310881E). All other primers and probes were obtained from TAG Copenhagen (Denmark). In a validation experiment using a control sample, a dilution series was produced and assayed for prostasin, PN-1, HAI$1 A, H A I-1 B$ and $\beta$-actin as described for the comparative $C_{t}$ method [39]. When $C_{t}$ values were plotted against log dilution it was shown that the assays are quantitative over a range of 256-fold dilution and that the PCR reactions have similar efficiencies provided that a threshold of 0.02 is used for prostasin and 0.2 is used for PN-1, HAI-1A, $H A I-1 B$, and $\beta$-actin. The threshold is a fixed fluorescence signal level above the baseline and the $\mathrm{C}_{\mathrm{t}}$ value of a sample is determined as the fractional cycle number where the sample's fluorescence signal exceeds the threshold. Prostasin, PN-1, HAI-1A, HAI-1B, and $\beta$-actin were quantified

Table I: Characteristics of cases and healthy individuals participating in this study

\begin{tabular}{|c|c|c|c|c|}
\hline Prostasin & Healthy & Cases & & \\
\hline & & Adenomas ${ }^{1}$ & & Carcinomas \\
\hline & & Mild/moderate dysplasia & Severe dysplasia & \\
\hline & $(n=23)$ & $(n=93)$ & $(n=13)$ & $(n=116)$ \\
\hline Men & 9 & 68 & 7 & 59 \\
\hline Women & 14 & 25 & 6 & 57 \\
\hline Mean age $+\mathbf{S D}^{2}$ & $56.3 \pm 4.6$ & $57.3 \pm 3.5$ & $54.8 \pm 3.1$ & $68.7 \pm 12.4$ \\
\hline
\end{tabular}

IThe adenomas are divided in groups according to diagnosed degree of dysplasia.

${ }^{2}$ There are significant differences in age among the four groups of healthy and affected individuals at $95 \%$ confidence level (Kruskal-Wallis test). 
separately in triplicates. The average standard deviation on the triplicates was $14 \%$ or less. The standard deviation on repeated measurements of the same sample (the control) in separate experiments was 20\%,11\%, 14\%, and $14 \%$ for prostasin, PN-1, HAI-1A and HAI-1B respectively, indicating the day-to-day variation of the assay. Independent PCR reactions of the same samples yielded a correlation coefficient of 0.85 for prostasin and 0.95 for $P N-1$. Negative controls (where the RNA was not converted into cDNA) and positive controls were included in all sets.

\section{Statistical analysis}

MiniTab Statistical Software, Release 13.1 Xtra (Minitab Inc.) and Graph Pad Prism 4 were used for the statistic calculations. The data were not adjusted for gender since the incidence ratio of colorectal cancer between the genders is $1: 1$ in Norway [40].

\section{Immunohistochemistry}

Tissue specimens were fixed in $4 \%$ formalin, paraffin embedded and processed for routine histology. Tissue sections were cleared with xylene and rehydrated in a graded series of alcohols and boiled in T-EG buffer (10 mM Tris, $0.5 \mathrm{mM}$ EDTA, $\mathrm{pH}=9$ ) for $20 \mathrm{~min}$ for antigen retrieval. The sections were blocked for $30 \mathrm{~min}$ in PBS containing $3 \%$ BSA and $0.1 \%$ Triton X-100 and then incubated at $4{ }^{\circ} \mathrm{C}$ overnight with mouse anti-prostasin antibody (BD Biosciences, cat nr. 612173) $(0.02 \mu \mathrm{g} / \mu \mathrm{l})$ and goat antihHAI-1 (RD System, cat nr. AF1048, diluted 1:1000). The slides were washed 3 times for 5 min with 3\% BSA in PBS and $0.1 \%$ Triton X-100 and incubated at room temperature for $45 \mathrm{~min}$ with the secondary antibody Alexa fluor 555 donkey anti-mouse and Alexa fluor 488 donkey antigoat. Afterwards, tissue sections were washed 3 times for 5 min with $3 \%$ BSA in PBS and $0.1 \%$ Triton X-100, followed by 4 times in PBS and finally mounted with DAPI H-1500 (Vector Laboratories Inc.). The sections were examined for the localization of prostasin subjected to laser conventional fluorescence microscopy. Sections where the primary antibodies were omitted served as controls.

\section{Results \\ Expression of prostasin and PN-I mRNA during carcinogenesis}

The mRNA levels of prostasin and PN-1 were measured in colon tissue samples from healthy individuals $(n=23)$, individuals with mild/moderate dysplasia $(n=93)$, individuals with severe dysplasia $(\mathrm{n}=13)$, and individuals with colorectal cancer $(n=116)$ by real-time RT-PCR. From individuals with dysplasia a sample of histologically normal tissue was used as well. From individuals with colorectal cancer two sample of histologically normal tissue from the surgically removed tissue were used. Ole sample was obtained as far away from the cancer tissue as possible (normal distant) and another sample obtained immediately adjacent to the cancer tissue (normal adja- cent). A good correlation between the mRNA and protein levels for both prostasin [26] and PN-1 [41] has previously been shown. The mRNA levels of prostasin, PN-1, HAI-1A and $H A I-1 B$ were normalised to the mRNA level of $\beta$-actin.

The range and the interquartile range of mRNA levels of prostasin normalised to $\beta$-actin are shown in Figure 1. When the prostasin mRNA level of healthy individuals was compared to normal or affected tissue from individuals with dysplasia or colorectal cancer no significant difference could be observed (Figure 1 and Table 2). However, the prostasin mRNA level of all adenomas and carcinomas combined was statistically significantly lower than the level in tissue from healthy individuals $(\mathrm{p}<0.05)$. There was also a significant difference when normal and affected tissue from the same individual were compared for individuals with mild/moderate dysplasia $(\mathrm{p}<0.001)$, severe dysplasia ( $\mathrm{p}<0.01)$, and for colorectal cancer both compared to the normal distant $(\mathrm{p}<0.05)$ and to the normal adjacent sample $(\mathrm{p}<0.01)$. This shows that the prostasin mRNA level is slightly but significant lower in mild/moderate dysplasia, severe dysplasia and colorectal cancer tissue as compared to normal tissue.

The range and the interquartile range of mRNA levels of $P N-1$ normalised to $\beta$-actin are shown in Figure 2 . The PN1 mRNA level showed an increase with increasing tumour grade in dysplastic and cancerous tissues whereas the normal tissue was not affected. A significant almost 3-fold increase ( $\mathrm{p}<0.001)$ of $P N-1$ mRNA was found in carcinomas as compared to corresponding tissues in healthy individuals (Table 2 and Figure 1). Comparing the level of $P N$ 1 in dysplastic and cancerous tissue with the corresponding normal tissue from the same individual, significant higher levels were encountered in mild/moderate dysplasia $(\mathrm{p}<0.001)$, severe dysplasia $(\mathrm{p}<0.05)$ and in carcinomas both when compared to the normal distant sample and with normal adjacent sample ( $\mathrm{p}<0.001)$, (Table 2$)$. In addition we found a significantly higher level of $P N-1$ mRNA when comparing affected tissue from mild/moderate and severe dysplasia combined (all adenomas) with carcinomas $(\mathrm{p}<0.001)$ using a one-way ANOVA and Tukey's post test. The PN-1 mRNA levels thus seem to be upregulated both at the transition from normal tissue to mild/moderate dysplasia and then again at the transition between dysplasia and cancer tissue whereas normal tissue is not affected.

Colorectal cancer can be staged according to Dukes' stage A-D where $\mathrm{D}$ is the most advanced and metastatic stage. Among the carcinomas in this study 23 carcinomas were designated as Dukes'stage A, 47 carcinomas as stage B, 39 carcinomas as stage $\mathrm{C}$ and none of the samples were classified as stage D. No tendency and no significant difference (one-way ANOVA and Tukey's post test for paired comparison) were seen when comparing the prostasin and 
Table 2: Prostasin mRNA levels in normal and affected tissues.

\begin{tabular}{|c|c|c|c|c|c|}
\hline Variable & $\begin{array}{l}\text { mRNA level in normal tissue } \\
\text { Mean (SD) }\end{array}$ & $\mathbf{P a}$ & $\begin{array}{l}\text { mRNA level in adenomas/ } \\
\text { carcinomas Mean (SD) }\end{array}$ & $\mathbf{P a}$ & $\mathbf{P b}$ \\
\hline \multicolumn{6}{|l|}{ Prostasin } \\
\hline Healthy individuals & $0.96(0.29)$ & & & & \\
\hline Mild/moderate & $1.10(0.38)$ & NS & $0.62(0.24)$ & NS & $<0.001$ \\
\hline Severe & $1.08(0.46)$ & NS & $0.73(0.50)$ & NS & $<0.01$ \\
\hline \multirow[t]{2}{*}{ Carcinoma distant adjacent } & $0.85(0.65)$ & NS & $0.61(0.60)$ & NS & $<0.05$ \\
\hline & $0.90(0.76)$ & NS & & & $<0.01$ \\
\hline All adenomas and carcinomas & $0.96(0.61)$ & NS & $0.62(0.48)$ & $<0.05$ & ND \\
\hline \multicolumn{6}{|l|}{ PN-I } \\
\hline Healthy individual & $0.022(0.030)$ & & & & \\
\hline Mild/moderate & $0.015(0.017)$ & NS & $0.041(0.028)$ & NS & $<0.001$ \\
\hline Severe & $0.010(0.003)$ & NS & $0.033(0.03 \mathrm{I})$ & NS & $<0.05$ \\
\hline \multirow[t]{2}{*}{ Carcinoma distant adjacent } & $0.028(0.027)$ & NS & $0.063(0.060)$ & $<0.001$ & $<0.001$ \\
\hline & $0.025(0.018)$ & NS & & & $<0.001$ \\
\hline
\end{tabular}

The mRNA levels were normalised to $\beta$-actin mRNA levels.

NS $=$ not significant

ND $=$ not determined

p value for the comparison to the expression levels in healthy individuals using a one-way ANOVA and Tukey's post test for paired comparisons.

a) $\mathrm{P}$ value for the comparison to the expression levels in healthy individuals using a one-way ANOVA and Tukey's post test for paired comparisons.

b) $\mathrm{p}$ value for the comparison of the expression levels in normal and affected tissue from the same individual using a paired t-test

PN-1 mRNA levels with the designated Dukes'stages. Likewise the adenomas were classified as either low-risk $(\mathrm{n}=$ 14) or high-risk $(n=91)$ adenomas using the criteria described in material and methods. No significant difference in the mRNA levels of either prostasin or $P N-1$ was seen when comparing high-risk and low-risk adenomas (one-way ANOVA and Tukey's post test for paired comparison). When the prostasin mRNA level in normal tissue from either healthy individuals or individuals with dysplasia or colorectal cancer was plotted against age we were unable to detect any age-related change in the prostasin mRNA level $(n=245$, age range 26-88) whereas the $P N-1$ mRNA level showed a slight increase with higher age. We were unable to detect any gender-related differences in the prostasin or PN-1 mRNA expression levels.

\section{Expression of HAI-IA and HAI-IB during carcinogenesis}

It is possible that prostasin activity is regulated by modulation of the ratio between HAI-1A and HAI-1B as it is not clear whether the two inhibitors have the same kinetic properties. The two HAI-1 transcripts differ by the coding region for 16 amino acids. We have previously shown that
HAI-1 is significantly down-regulated in both normal and affected tissue from individuals with adenomas and carcinomas [34]. In the present study we have investigated a subset of the cohort using two quantitative RT-PCR assays specific for $H A I-1 A$ and $H A I-1 B$ respectively. mRNA levels for $H A I-1 A$ and $H A I-1 B$ were determined in colon tissue samples from healthy individuals $(\mathrm{n}=14)$, in healthy and affected tissue from individuals with mild/moderate dysplasia $(\mathrm{n}=19)$ and in healthy and tumour tissue from patients with colorectal cancer $(n=24)$. Figure 3 shows the range and interquartile range of mRNA levels of $H A I$ $1 A, H A I-1 B$ and the radio of $H A I-1 A / H A I-1 B$ normalised to $\beta$-actin. The levels of HAI-1A and HAI-1B mRNA found are virtually identical in all tissues examined with the levels of HAI-1 found previously [34]. Both HAI-1A and HAI$1 \mathrm{~B}$ are thus progressively down-regulated with increasing tumour grade. We thus found no statistically significant difference between the ratios of $H A I-1 A / H A I-1 B$ in the different tissues tested. These data suggest that there is no regulation in the splicing of the HAI-1 transcript during colorectal cancer carcinogenesis. 


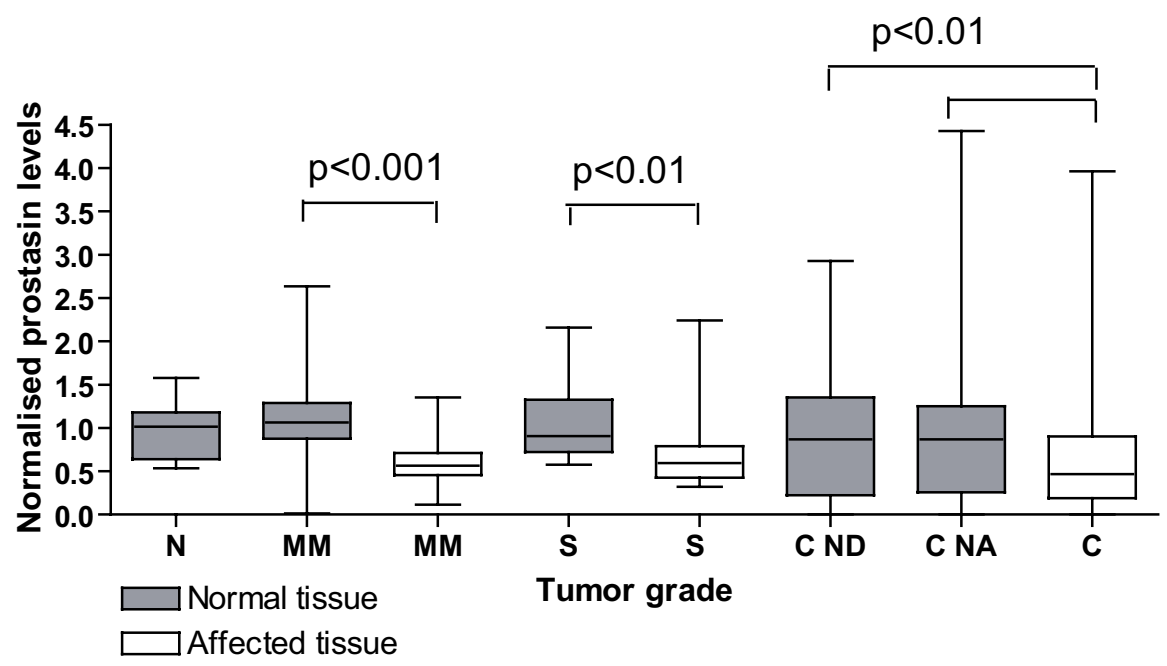

\section{Figure I}

The levels of prostasin mRNA were determined by real-time RT-PCR from healthy individuals (N), individuals with mild/moderate dysplasia (M/M), severe dysplasia (S) or carcinomas (C). Both normal (grey bars) and affected (white bars) tissues were examined from each individual. From colorectal cancer patients one sample of histological normal tissue was taken as far away from the colorectal cancer tissue as allowed by the surgically removed tissue (normal distant, here designated ND) and one sample of histological normal tissue was taken immediately adjacent to the colorectal cancer tissue (normal adjacent here designated NA). mRNA levels were normalised to the $\beta$-actin mRNA level. The box shows the interquartile range, the whiskers the range and the median is indicated by a vertical line.

\section{Localization of prostasin and HAl-I by immunohistochemistry}

Normal and cancerous tissues from five colorectal cancer patients were analysed to investigate the sub-cellular localization of prostasin and HAI-1. Formalin-fixed paraffin-embedded tissue sections were immunohistochemically co-stained for prostasin and HAI-I. In normal colorectal tissue, prostasin was detected mainly on the apical plasma membrane - with only minor staining of the basolateral plasma membrane (Figure 4A and 4D). HAI-1 was found mainly on the basolateral plasma membrane mostly not co-localizing with prostasin (Figure 4B and 4D). This is consistent with previous findings which showing that prostasin is located primarily on the apical plasma membrane [23], and mostly secreted from the apical side of polarized epithelial cells [42]. Likewise previous findings show that HAI-1 is located primarily on the basolateral plasma membrane of a range of polarized epithelial cells [43-46]. In some colorectal cancer tissue specimens we found a similar polarized apical staining of prostasin and basolateral staining of HAI- 1 as seen in histologically normal tissue (Figure $4 \mathrm{E}, \mathrm{F}, \mathrm{G}$, and $4 \mathrm{H}$ ). In contrast prostasin and HAI-1 were co-localizing in other colorectal cancer tissue specimens all along the cell periphery suggesting that the polarization of the cells has been lost during carcinogenesis (Figure 4L, J, K, and 4L).

\section{Discussion}

In the present study we have determined the mRNA levels of prostasin, PN-1,HAI-1A and HAI-1B during colorectal cancer carcinogenesis. It has previously been shown that over-expression of prostasin in mammary and prostate cancer cells reduces the invasive properties of cancer cells $[23,24]$ and that high prostasin expression in gastric tumours is associated with longer survival [25]. It could thus be speculated that the transition from severe dysplasia to cancer is accompanied by a transcriptional decrease in prostasin expression and/or a down-regulation of prostasin activity via up regulation of one or more enzymatic inhibitors of prostasin. In the present study we found modest but significantly lower levels of prostasin mRNA in mild/moderate dysplasia, severe dysplasia and colorectal cancer tissues combined as compared to corresponding normal tissues from healthy individuals. In a previous study a similar minor but significant down-regulation was seen when comparing normal and affected tissue from gastric cancer patients [25]. Our results do not show any transcriptional down-regulation of prostasin accompanying the transition between severe dysplasia and colorectal cancer. However, the mRNA levels of the inhibitor of prostasin, $P N-1$ increase at both the transition between normal tissue and mild/moderate dysplasia and again at the transition between severe dysplasia and colorectal cancer.

For PN-1 to be a physiologically relevant inhibitor of prostasin it is required that $\mathrm{PN}-1$ and prostasin have physical access to each other. PN-1 belongs to the serpin family of secretory proteins. We have previously shown that five other members of the serpin family are secreted to both 


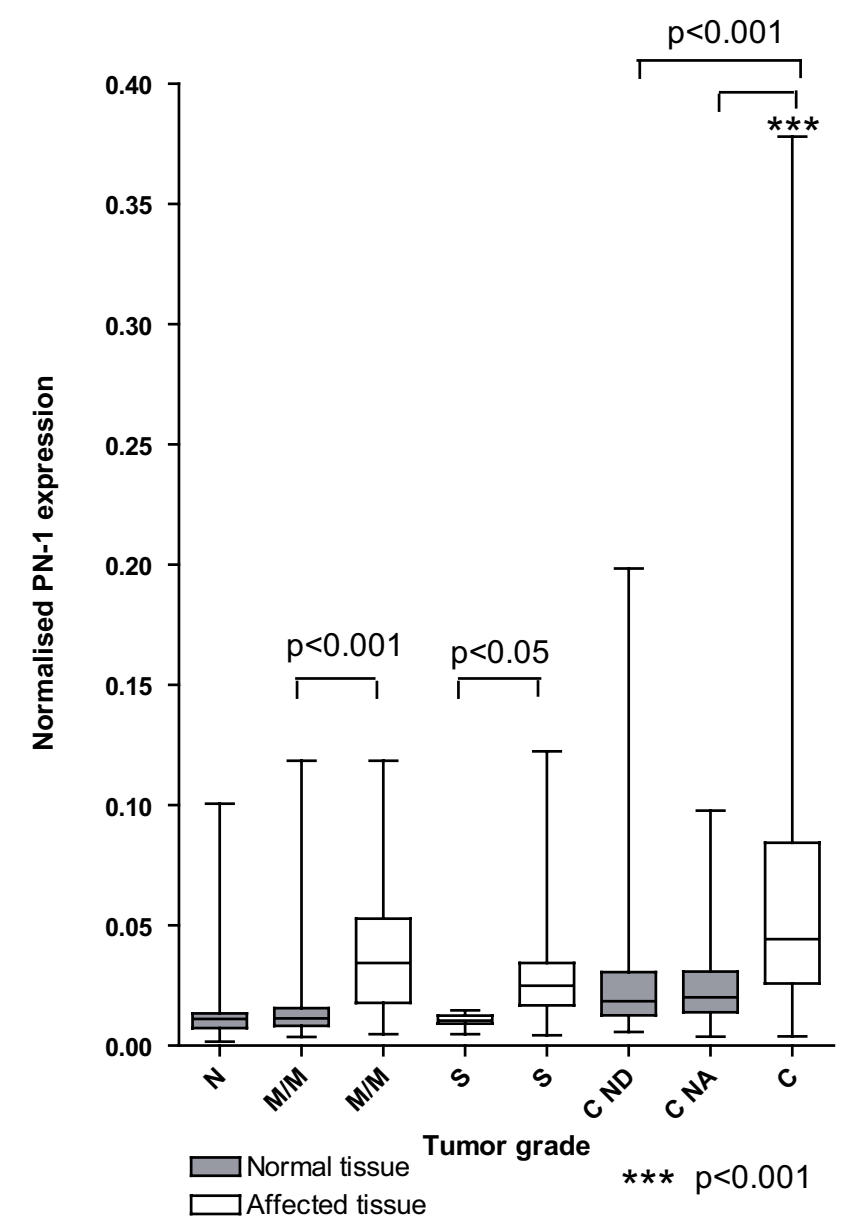

HAI-1A
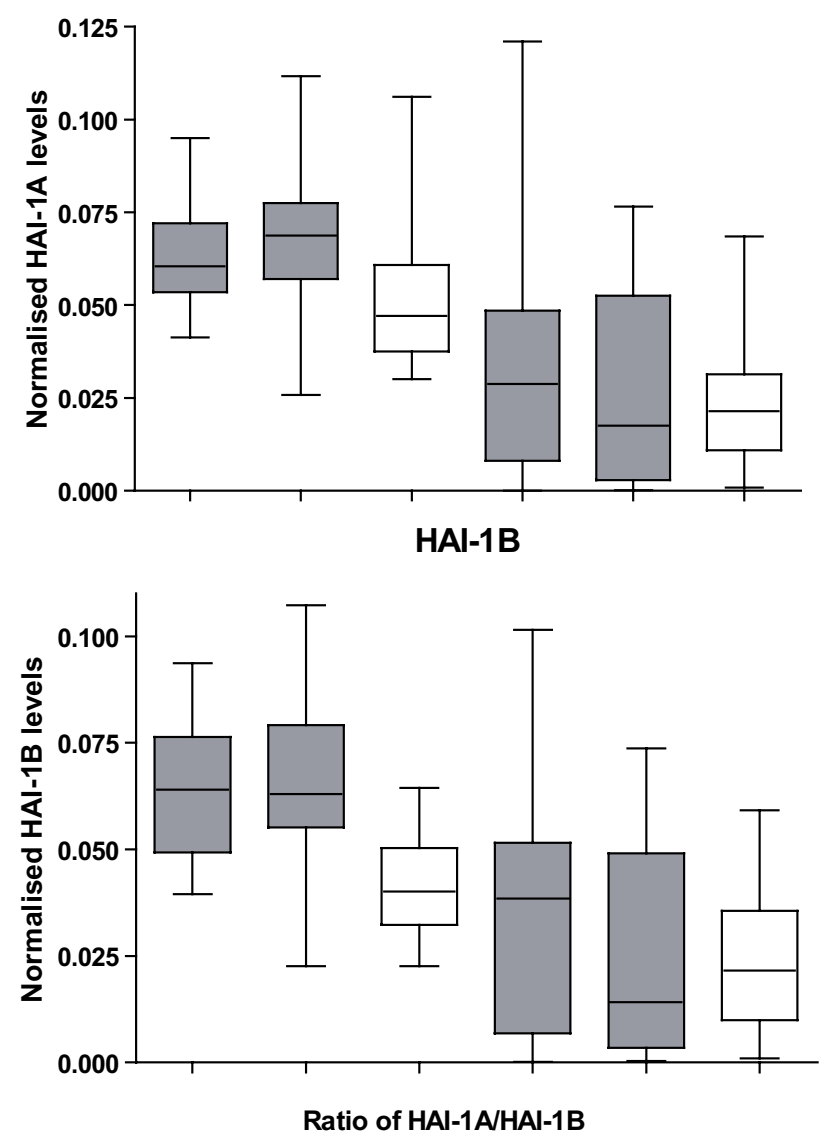

Figure 2

The levels of protease nexin-I (PN-I) mRNA were determined by real-time RT-PCR from healthy individuals $(\mathbf{N})$, individuals with $\mathrm{mild} /$ moderate dysplasia $(M / M)$, severe dysplasia (S) or carcinomas (C). Symbols and group designations are the same as in Figure I. mRNA levels were normalised to the $\beta$-actin mRNA level. The box shows the interquartile range, the whiskers the range and the median is indicated by a vertical line.

the apical and the basolateral side of the polarized epithelial cell line, MDCK, albeit at different ratios [47]. Similar results were obtained for the Caco- 2 cell line, derived from a human colonic adenocarcinoma (Vogel et al., unpublished results). There are therefore no indications that PN-1 in the extracellular fluid has restricted access to plasma membrane-bound prostasin. Consequently, it is possible that PN-1 plays an important role in down-regulating the enzymatic activity of prostasin in cancer tissue resulting in more invasive cell behaviour.

Prostasin is inhibited not only by PN-1 but also by HAI-

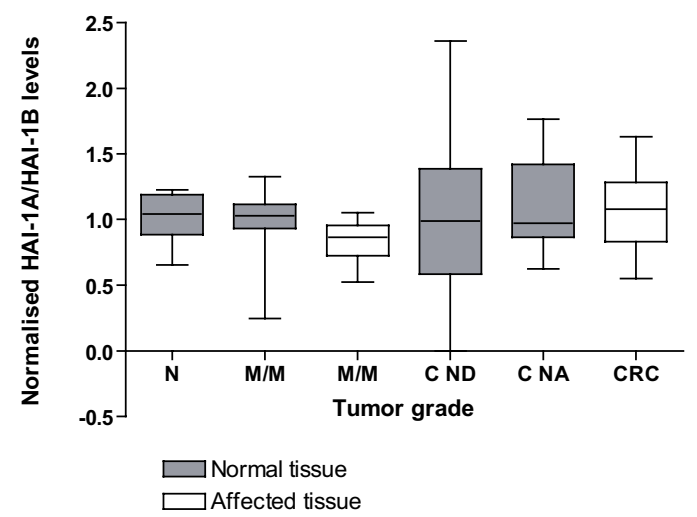

Figure 3

The levels of HAI-IA and HAI-IB mRNA were determined by real-time RT-PCR from healthy individuals $(\mathbf{N})$, individuals with $\mathrm{mild} / \mathrm{moderate}$ dysplasia (M/M) or carcinomas (C). Symbols and group designations are the same as in Figure I. mRNA levels were normalised to the $\beta$-actin mRNA level. The box shows the interquartile range, the whiskers the range and the median is indicated by a vertical line. 

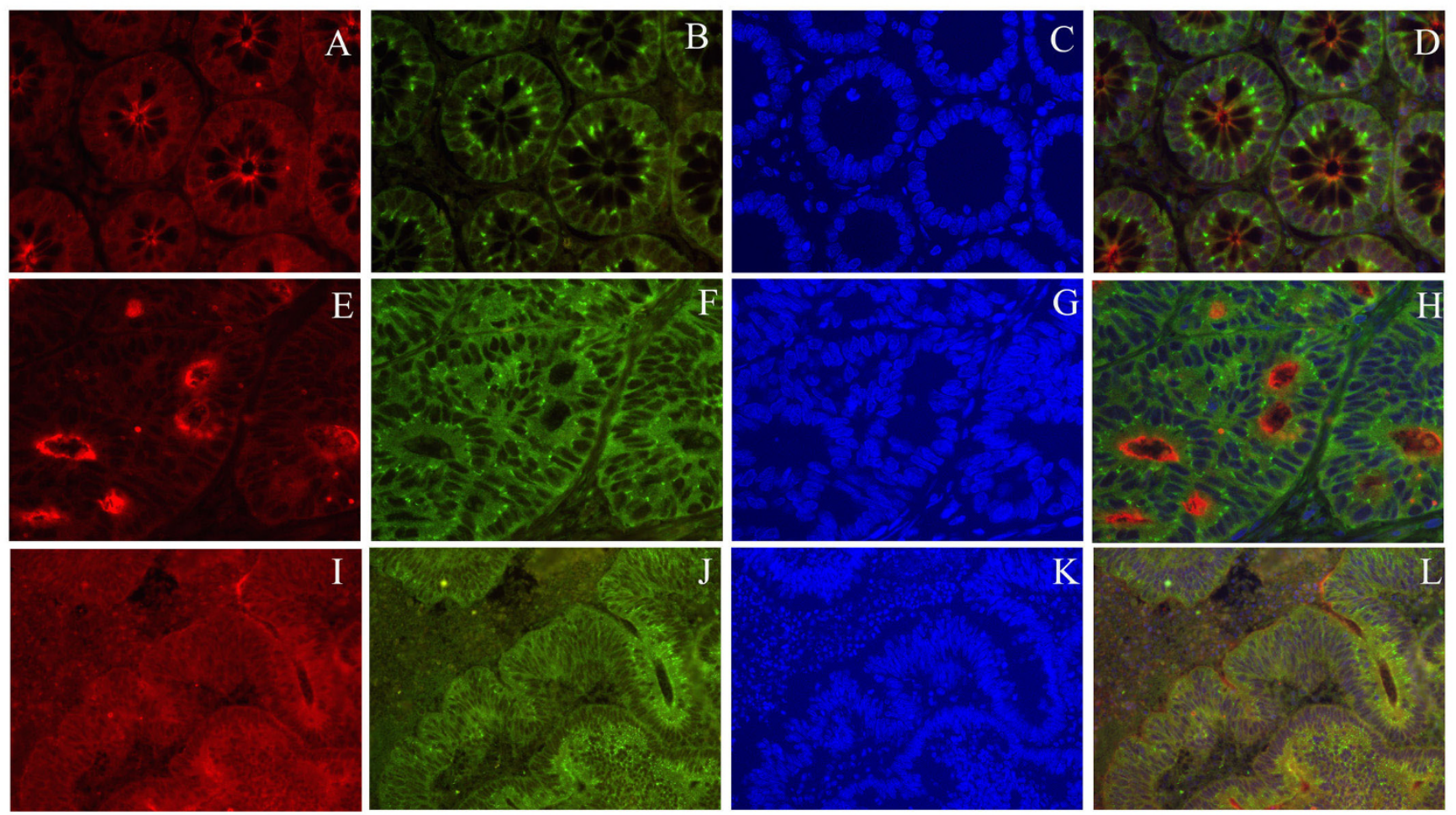

\section{Figure 4}

Prostasin and HAI-I are located on the apical and the basolateral side, respectively in normal tissue and some colorectal cancer tissue specimens whereas they are co-localized in other colorectal cancer tissues specimens. Tissue sections of formalin-fixed, paraffin-embedded normal and malignant tissue from colorectal cancer patients was immunohistochemically stained for prostasin (A, E, I) and HAI- I (B, F, J). Histological normal colorectal tissue from a cancer patient (upper panel, A, B, C and D) and two examples of colorectal cancer tissue are shown (middle and lower panel). Nuclei were visualized by DAPI staining (C, G, and $\mathrm{K})$.

of HAI-1 mRNA is decreased by 3 -fold during colorectal cancer carcinogenesis using an assay that does not distinguish between $H A I-1 A$ and $H A I-1 B$ [34]. In the present study we have shown that HAI-1A and HAI-1B have expression patterns virtually identical and indistinguishable from the expression pattern of $H A I-1$ previously found [34] and that the ratio of $H A I-1 A / H A I-1 B$ remains the same in all tissues investigated during colorectal cancer carcinogenesis. Therefore, the splicing of HAI-1 mRNA is not regulated during carcinogenesis. In the present study we found limited co-localization of prostasin and HAI-1 in normal tissue, as HAI-1 is located mainly on the basolateral plasma membrane and prostasin is located on the apical plasma membrane. This probably does not mean that their interactions is limited due to physical separation as we have previously shown that HAI-1 is transcytosed from the basolateral plasma membrane to the apical plasma membrane [43]. It is thus possible that HAI-1 interacts with prostasin at the apical plasma membrane.

The enzymatic activity of prostasin is influenced both by the levels of PN-1, HAI-1A and HAI-1B and probably also by the expression levels of other as yet undiscovered inhibitors of prostasin. The relative physiological importance of PN-1, HAI-1A and HAI-1B as inhibitors of prostasin is at present unclear. PN-1 is an inhibitor of not only prostasin, but also of uPA, tPA, thrombin, plasmin, trypsin [48] and matriptase [21] and it forms an essentially non-reversible binding to its target protease like most other serpins [49]. Apart from physical accessibilities, the relative abundances of other target proteases may become an important issue as an abundant target for PN1 may "quench" a large amount of PN-1 by forming a non-reversible complex with it. However, the co-purification of prostasin in complex with PN-1 [49] suggests that $\mathrm{PN}-1$, at least to some degree plays a role as an inhibitor of prostasin in vivo. Likewise prostasin-HAI-1B complexes have been purified from a cell line [11], suggesting that it is a physiologically relevant inhibitor of prostasin. Further knowledge about the binding kinetics between the proteases and their inhibitors is needed to clarify the relative importance of PN-1 and HAI-1 isoforms as inhibitors of prostasin. 


\section{Conclusion}

Proteases have for a long time been thought to play an important role in the growth of cells both during tissue remodelling and invasive growth. However, the action of proteases may be regulated not necessarily by the expression of the protease but by regulating the expression of its inhibitors. Our data shows that elevated mRNA levels for prostasins inhibitor, $P N-1$, coincides with acquisition of malignant properties, whereas the mRNA level of prostasin is relative stable during colorectal cancer carcinogenesis. However, further investigations are necessary to understand the role of prostasin, PN-1, HAI-1A and HAI-1B for invasive growth and malignant progression.

\section{Competing interests}

The authors declare that they have no competing interests.

\section{Authors' contributions}

LV conceived the idea of the study. EHK designed the cohort and collected the samples. LV and EHK extracted the RNA. LV and JB designed and validated primers and probes and performed the statistical analyses. JS-P performed the immunohistochemistry. IMBL evaluated the tissue sections. JS-P, SF and LV prepared the figures. KMT and EKH administrated the KAM study. LV and JS-P wrote the first draft of the manuscript. All authors helped interpret the results, writing the manuscript and read and approved the final version.

\section{Acknowledgements}

We thank Christel Halberg for kind technical help and assistance.

This work was supported by The Norwegian Cancer Society, Telemark University College, the Norwegian Colorectal Cancer Prevention (NORCCAP) study, Eastern Norway Regional Health Authority, The cluster of Cell Biology at the University of Copenhagen and The Lundbeck Foundation.

\section{References}

I. Lopez-Otin C, Matrisian LM: Tumour micro environment Opinion - Emerging roles of proteases in tumour suppression. Nature Reviews Cancer 2007, 7:800-808.

2. Balbin M, Fueyo A, Tester AM, Pendas AM, Pitiot AS, Astudillo A, Overall CM, Shapiro SD, Lopez-Otin C: Loss of collagenase-2 confers increased skin tumor susceptibility to male mice. Nature Genetics 2003, 35:252-257.

3. McCawley LJ, Crawford HC, King LE, Mudgett J, Matrisian LM: A protective role for matrix metalloproteinase-3 in squamous cell carcinoma. Cancer Research 2004, 64:6965-6972.

4. Overall CM, Kleifeld O: Tumour microenvironment - Opinion - Validating matrix metalloproteinases as drug targets and anti-targets for cancer therapy. Nature Reviews Cancer 2006, 6:227-239.

5. Yu JX, Chao L, Chao J: Molecular cloning, tissue-specific expression, and cellular localization of human prostasin mRNA. J Biol Chem 1995, 270: I3483-I3489.

6. Vallet V, Chraibi A, Gaeggeler HP, Horisberger JD, Rossier BC: An epithelial serine protease activates the amiloride-sensitive sodium channel. Nature 1997, 389:607-610.

7. Verghese GM, Gutknecht MF, Caughey GH: Prostasin regulates epithelial monolayer function: cell-specific GpldI-mediated secretion and functional role for GPI anchor. American Journal of Physiology-Cell Physiology 2006, 291:CI258-CI 270.

8. Vassalli JD, Huarte J, Bosco D, Sappino AP, Sappino N, Velardi A, Wohlwend A, Erno H, Monard D, Belin D: Protease-nexin I as an androgen-dependent secretory product of the murine seminal vesicle. EMBO J 1993, I 2:187|-1878.

9. Chen LM, Zhang XC, Chai KX: Regulation of prostasin expression and function in the prostate. Prostate 2004, 59: I-I2.

10. Knauer DJ, Thompson JA, Cunningham DD: Protease Nexins Cell-Secreted Proteins That Mediate the Binding, Internalization, and Degradation of Regulatory Serine Proteases. Journal of Cellular Physiology 1983, I I 7:385-396.

II. Fan B, Wu TD, Li W, Kirchhofer D: Identification of hepatocyte growth factor activator inhibitor- IB as a potential physiological inhibitor of prostasin. J Biol Chem 2005, 280:345 I 3-34520.

12. Kirchhofer D, Peek M, Li W, Stamos J, Eigenbrot C, Kadkhodayan S, Elliott JM, Corpuz RT, Lazarus RA, Moran P: Tissue expression, protease specificity, and Kunitz domain functions of hepatocyte growth factor activator inhibitor-IB (HAI-IB), a new splice variant of HAl-I. J Biol Chem 2003, 278:3634I-36349.

13. Netzel-Arnett S, Currie BM, Szabo R, Lin CY, Chen LM, Chai KX, Antalis TM, Bugge TH, List K: Evidence for a matriptase-prostasin proteolytic cascade regulating terminal epidermal differentiation. Journal of Biological Chemistry 2006, 28 I:3294I-32945.

14. Oberst MD, Chen LYL, Kiyomiya KI, Williams CA, Lee MS, Johnson $M D$, Dickson RB, Lin CY: HAl-I regulates activation and expression of matriptase, a membrane-bound serine protease. American Journal of Physiology-Cell Physiology 2005, 289:C462-C470.

15. Oberst MD, Williams CA, Dickson RB, Johnson MD, Lin CY: The activation of matriptase requires its noncatalytic domains, serine protease domain, and its cognate inhibitor. J Biol Chem 2003, 278:26773-26779.

16. List K, Szabo R, Wertz PW, Segre J, Haudenschild CC, Kim SY, Bugge $\mathrm{TH}$ : Loss of proteolytically processed filaggrin caused by epidermal deletion of Matriptase/MT-SPI. J Cell Biol 2003, 163:901-910.

17. Leyvraz C, Charles RP, Rubera I, Guitard M, Rotman S, Breiden B, Sandhoff K, Hummler $E$ : The epidermal barrier function is dependent on the serine protease CAPI/Prss8. Journal of Cell Biology 2005, I 70:487-496

18. List K, Haudenschild CC, Szabo R, Chen W, Wahl SM, Swaim W, Engelholm LH, Behrendt N, Bugge TH: Matriptase/MT-SPI is required for postnatal survival, epidermal barrier function, hair follicle development, and thymic homeostasis. Oncogene 2002, 2 I :3765-3779.

19. Bruns JB, Carattino MD, Sheng S, Maarouf AB, Weisz OA, Pilewski JM, Hughey RP, Kleyman TR: Epithelial Na+ channels are fully activated by furin- and prostasin-dependent release of an inhibitory peptide from the gamma-subunit. J Biol Chem 2007, 282:6153-6160.

20. Chen MQ, Fu YY, Lin CY, Chen LM, Chai KX: Prostasin induces protease-dependent and independent molecular changes in the human prostate carcinoma cell line PC-3. Biochimica et Biophysica Acta-Molecular Cell Research 2007, I 773: I I 33-I I 40.

21. Myerburg MM, McKenna EE, Luke CJ, Frizzell RA, Kleyman TR, Pilewski JM: Prostasin expression is regulated by airway surface liquid volume and is increased in cystic fibrosis. American Journal of Physiology-Lung Cellular and Molecular Physiology 2008, 294:L932-L94I.

22. List K, Szabo R, Molinolo A, Sriuranpong V, Redeye V, Murdock T, Burke B, Nielsen BS, Gutkind S], Bugge TH: Deregulated matriptase causes ras-independent multistage carcinogenesis and promotes ras-mediated malignant transformation. Genes \& Development 2005, 19:1934-1950.

23. Chen LM, Hodge GB, Guarda LA, Welch JL, Greenberg NM, Chai KX: Down-regulation of prostasin serine protease: a potential invasion suppressor in prostate cancer. Prostate 2001, 48:93-103.

24. Chen LM, Chai KX: Prostasin serine protease inhibits breast cancer Invasiveness and is transcriptionally regulated by promoter DNA methylation. International Journal of Cancer 2002, 97:323-329.

25. Sakashita K, Mimori K, Tanaka F, Tahara K, Inoue H, Sawada T, Ohira M, Hirakawa K, Mori M: Clinical Significance of Low Expression of Prostasin mRNA in Human Gastric Cancer. Journal of Surgical Oncology 2008, 98:559-564.

26. Takahashi S, Suzuki S, Inaguma S, Ikeda Y, Cho YM, Hayashi N, Inoue T, Sugimura Y, Nishiyama N, Fujita T, Chao J, Ushijima T, Shirai T: Down-regulated expression of prostasin in high-grade or 
hormone-refractory human prostate cancers. Prostate 2003, 54:187-193.

27. Gao S, Krogdahl A, Sorensen JA, Kousted TM, Dabelsteen E, Andreasen PA: Overexpression of protease nexin-I mRNA and protein in oral squamous cell carcinomas. Oral Oncol 2007, 44:309-313.

28. Candia BJ, Hines WC, Heaphy CM, Griffith JK, Orlando RA: Protease nexin- $I$ expression is altered in human breast cancer. Cancer Cell Int 2006, 6:16.

29. Buchholz M, Biebl A, Neesse A, Wagner M, Iwamura T, Leder G, Adler G, Gress TM: SERPINE2 (protease nexin I) promotes extracellular matrix production and local invasion of pancreatic tumors in vivo. Cancer Res 2003, 63:4945-495I.

30. Rao JS, Kahler CB, Baker JB, Festoff BW: Protease nexin I, a serpin, inhibits plasminogen-dependent degradation of muscle extracellular matrix. Muscle Nerve 1989, 12:640-646.

31. Stone SR, Hermans JM: Inhibitory mechanism of serpins. Interaction of thrombin with antithrombin and protease nexin I. Biochemistry 1995, 34:5164-5172.

32. Eaton DL, Baker JB: Evidence that a variety of cultured cells secrete protease nexin and produce a distinct cytoplasmic serine protease-binding factor. J Cell Physiol 1983, I 17: $175-182$.

33. Gurwitz D, Cunningham DD: Neurite outgrowth activity of protease nexin-I on neuroblastoma cells requires thrombin inhibition. J Cell Physiol 1990, I42: I55-162.

34. Vogel LK, Saebo M, Skjelbred CF, Abell K, Pedersen ED, Vogel U, Kure EH: The ratio of Matriptase/HAI-I mRNA is higher in colorectal cancer adenomas and carcinomas than corresponding tissue from control individuals. Bmc Cancer 2006, 6:176-183

35. Yamauchi M, Kataoka H, Itoh H, Seguchi T, Hasui Y, Osada Y: Hepatocyte growth factor activator inhibitor types $I$ and 2 are expressed by tubular epithelium in kidney and downregulated in renal cell carcinoma. Journal of Urology 2004, | 71:890-896.

36. Zeng L, Cao J, Zhang X: Expression of serine protease SNCI $9 /$ matriptase and its inhibitor hepatocyte growth factor activator inhibitor type $I$ in normal and malignant tissues of gastrointestinal tract. World Journal of Gastroenterology 2005, I I:6202-6207.

37. Gondal G, Grotmol T, Hofstad B, Bretthauer M, Eide TJ, Hoff G: The Norwegian Colorectal Cancer Prevention (NORCCAP) screening study. Scandinavian Journal of Gastroenterology 2003, 38:635-642.

38. Clinical Trials 2007 [http://clinicaltrials.gov]

39. Johnson MR, Wang KS, Smith JB, Heslin MJ, Diasio RB: Quantitation of dihydropyrimidine dehydrogenase expression by realtime reverse transcription polymerase chain reaction. Analytical Biochemistry 2000, 278:175-184.

40. The Cancer Registry of Norway: Cancer in Norway 200I. Oslo: InfoPrint as, 2004.

41. Gao S, Krogdahl A, Sorensen JA, Kousted TM, Dabelsteen E, Andreasen PA: Overexpression of protease nexin-I mRNA and protein in oral squamous cell carcinomas. Oral Oncol 2007, 44:309-313.

42. Verghese GM, Gutknecht MF, Caughey GH: Prostasin regulates epithelial monolayer function: cell-specific GpldI-mediated secretion and functional role for GPI anchor. American Journal of Physiology-Cell Physiology 2006, 29 I:CI258-CI 270.

43. Godiksen S, Selzer-Plon J, Pedersen EDK, Abell K, Rasmussen HB, Szabo R, Bugge TH, Vogel LK: Hepatocyte growth factor activator inhibitor-I has a complex subcellular itinerary. Biochemical Journal 2008, 4I 3:25I-259.

44. Shimomura T, Denda K, Kitamura A, Kawaguchi T, Kito M, Kondo J, Kagaya S, Qin L, Takata H, Miyazawa K, Kitamura N: Hepatocyte growth factor activator inhibitor, a novel Kunitz-type serine protease inhibitor. Journal of Biological Chemistry 1997, 272:6370-6376.

45. Oberst M, Anders J, Xie B, Singh B, Ossandon M, Johnson M, Dickson $\mathrm{RB}$, Lin CY: Matriptase and HAI-I are expressed by normal and malignant epithelial cells in vitro and in vivo. Am J Pathol 200I, I 58: | $30|-| 3||$.

46. Kataoka $H$, Suganuma $T$, Shimomura $T$, Itoh $H$, Kitamura $N$, Nabeshima K, Koono M: Distribution of hepatocyte growth factor activator inhibitor type I (HAI-I) in human tissues. Cellular surface localization of HAI-I in simple columnar epithelium and its modulated expression in injured and regenerative tissues. J Histochem Cytochem 1999, 47:673-682.

47. Vogel LK, Larsen JE: Apical and non-polarized secretion of serpins from MDCK cells. FEBS Lett 2000, 473:297-302.

48. Irving JA, Pike RN, Lesk AM, Whisstock JC: Phylogeny of the serpin superfamily: Implications of patterns of amino acid conservation for structure and function. Genome Research 2000, I0:1845-1864.

49. Chen LM, Zhang $X$, Chai KX: Regulation of prostasin expression and function in the prostate. Prostate 2004, 59:1-12.

\section{Pre-publication history}

The pre-publication history for this paper can be accessed here:

http://www.biomedcentral.com/1471-2407/9/201/pre pub
Publish with Bio Med Central and every scientist can read your work free of charge

"BioMed Central will be the most significant development for disseminating the results of biomedical research in our lifetime. "

Sir Paul Nurse, Cancer Research UK

Your research papers will be:

- available free of charge to the entire biomedical community

- peer reviewed and published immediately upon acceptance

- cited in PubMed and archived on PubMed Central

- yours - you keep the copyright

Submit your manuscript here:

http://www.biomedcentral.com/info/publishing_adv.asp
BioMedcentral 